\title{
Reform and Innovation of Practical Teaching in Application-oriented Universities
}

\author{
Chen Li'e \\ Quanzhou Normal University \\ Introduction to the author: Chen Li'e, born in April, 1974 in Jinjiang, Fujian Province, female, the Han \\ Nationality, bachelor degree, currently working in Quanzhou Normal University
}

Keywords: practical teaching in application-oriented university; essential problems; reform and innovation; cause of teaching problems

\begin{abstract}
With the continuous development of the society, people have been proposing new standards and requirements for university teaching, i.e., colleges and universities should pay attention to practical teaching in development and reform and improve teaching methods in practical teaching; furthermore, reform and innovation of practical teaching shall be realized. In practical teaching, though many educators have realized the importance of practical teaching, many problems appear in practical teaching situations, which are the disadvantage of fulfilling the requirements and standards of education department and relative personnel. This paper starts from the perspective of practical teaching problems in application-oriented university and studies the causes of practical teaching problems, thereby proposing effective improvement measures for reform and innovation for practical teaching in application-oriented university.
\end{abstract}

\section{Introduction}

With the continuous development of the market, people have a new definition of " talents", and over time, the market has begun to " rob" comprehensive application-oriented talents step by step. Thus, in order to meet the market demand, applied undergraduate colleges and universities have become the colleges and universities which people attach great importance to in the market. Thus, in this situation, people pay more and more attention to the practical teaching quality of application-oriented universities. However, due to the reasons that some universities' own measures are not in place and many factors interfere in the teaching process when implementing practical teaching in application-oriented universities, it is impossible for them to carry out practical teaching successfully. Therefore, in the current good market situation, the effective reform and innovation of practical teaching in colleges and universities is a problem that needs to be solved urgently by relevant personnel in colleges and universities.

\section{Problems in Practical Teaching in Application-oriented University}

Compared with other universities, application-oriented universities pay more attention to students' practical ability, so their speed of implementation is faster than that of other universities. However, with the continuous development of the market, people have had new requirements for talents, which makes it impossible for talents from application-oriented universities to satisfy the demands of the market. The major problems are related to problems in practical teaching, which are as follows:

\subsection{Application-oriented universities still apply traditional teaching methods}

Though the start of application-oriented universities is higher than that of other universities, it does not mean they get rid of the constraints of traditional teaching. In practical circumstances, application-oriented universities still adopt traditional teaching methods. For example, they are still teacher-centered and they still adopt cramming method, i.e., teachers teach teaching content with their mouth, they do not pay attention to students' central status, the teaching equipment is simple 
and crude, and they still write relative teaching contents on the blackboard without knowing modern computer teaching equipment. They still "infuse" too many contents to students in order to have the students obtain good grades, so students do not have the freedom to dominate their time and space; interaction between teacher and students is lacked, so students can only accept what the teachers say blindly, which not only repress students' practical and innovative awareness, but also makes students only be able to "imitate" without being able to operate practically. From the above, we can know that application-oriented universities still adopt traditional teaching methods, which are bound to cause students' poor practical ability and innovative awareness, and students' problem-analyzing ability and problem-solving abilities are bound to be influenced; in the meantime, students' innovative awareness cannot be stimulated well.

\subsection{Insufficient attention to practical teaching}

Though application-oriented universities belong to practical universities, they have not paid sufficient attention to practical teaching. For example, educators arrange little experimental curriculum in teaching design; even if there is experimental curriculum, not enough practical teaching contents are arranged. In addition, if students' practical abilities are to be improved in practical teaching, great teaching conditions should be arranged. However, in actual circumstances, many application-oriented universities do not set up good practical teaching base and professional labs for students, so many university students have not had close contact with enterprises even after their graduation. When it is time for them to start to work, they cannot fit the requirements of the post since they do not understand the construction of the enterprises and detailed process of operation.

\subsection{Unsuitable assessment system for students}

If barriers for students are to be found fundamentally and better teaching programs are to be formulated, a flexible assessment system should be formulated. However, "final examination" is adopted for most application-oriented universities. Though scores of final examinations can reflect students' practical learning achievements to some extent, the result is not perfect. Since people choose to have one final exam in one term, which not only cannot reflect the link of practical operation, but also makes the exam stiff and stereotyped. When people look at this test method from objective perspective, people would find that this test method might have certain active effects. However, it would create two obvious effects to some extent, i.e., students might have rote memorization and study temporarily in order to pass the exam; in addition, universities cannot identify students' real practical learning effects; furthermore, universities cannot formulate pertinent teaching problems for students and students cannot have a clear understanding of their disadvantages. In conclusion, such an assessment system goes against cultivating students' innovation ability and strengthening students' practical operation ability.

\subsection{Teachers with high professional skills and qualities are in shortage in universities}

A direct element influencing the efficiency of practical teaching is teachers' professional qualities and professional skills. Therefore, application-oriented universities need to bring in teachers with high professional skills and qualities. However, in the process of practical teaching, most teachers' professional standard cannot satisfy the requirement of practical teaching. Since the professional ability of most teachers who undertake practical teaching are basically the same with normal students, they cannot complete tasks of universities well in practical teaching, nor can they complete people's new requirements and standards that people propose for universities. Besides, since universities do not have teachers participate in the training of practical teaching regularly, which not only goes against improving teachers' s professional skills and qualities, but also goes against accelerating the process of practical teaching.

\section{Major Reasons for Practical Teaching Problems}

In practical teaching, teacher is a major influence factor that influences students. Therefore, if 
universities want to implement practical teaching, teachers need to have a correct understanding of practical teaching, i.e., they need to realize that application-oriented education is not equal to vocational college education. However, most teachers have not realized this. In practical teaching, they still adopt traditional teaching means, i.e., they still adopt the "cramming method", only paying attention to training students' theoretical knowledge, while neglecting their dominant role and the cultivation of their practical abilities. In practical teaching, teachers only adopt traditional teaching methods without making use of modern computer teaching equipment, so they cannot guarantee the quality of practical teaching.

Besides, another influence factor of teaching quality is that universities have not provided enough capital and technical support for teachers. From the perspective of universities, teachers' endeavor is the only thing that is needed for implementing practical activities, and a large quantity of capital is not necessary. However, if universities do not provide sufficient teaching resources for teachers, teachers may not be able to integrate students' characteristics with teaching resources, which hinders teachers from completing teaching targets and cultivating students' correspondent abilities. For example, universities do not set up well-established practical teaching bases and professional labs, nor do they bring in modern computer teaching equipment for teachers. Therefore, educators feel that "they only get half the result with twice the effort", which is a heavy blow to teachers' enthusiasm to some extent.

Therefore, in the process of application-oriented practical teaching, both educators' teaching methods and universities' attention to practical teaching are important elements that influence practical teaching. If universities' features are to be exerted well, both educators and universities need to regard students as development goals, provide a good platform of practical learning for students and truly make students' major fit with demands of the society.

\section{Effective Measures for Reform and Innovation of Practical Teaching}

From the above investigation, it is clear that at present, many problems emerge in practical teaching of application-oriented universities. If universities want their students' major fit requirements of the society, they need to start from market demands and formulate specific measures of innovation and reform at problems in practical teaching of application-oriented universities, and the specific measures are as follows:

\subsection{Providing learning platform for students by cooperation between school and enterprise}

If university students' employment efficiency and quality is to be guaranteed, everything needs to be practical, and reform and innovation need to be conducted at practical teaching. The specific measures are as follows, i.e., "strengthening cooperation between school and enterprise". During cooperation between school and enterprise, universities and enterprises need to have the cooperation mode of "reasonable input and efficient output". They should guarantee university students' employment efficiency and quality fundamentally and provide more realistic employment situation for students. If schools want to protect students effectively, they need to exclude hidden dangers of cooperation at the beginning. Therefore, the following contents need to be noticed, i.e., to implement cooperation between school and enterprise, firstly, universities and enterprises need to reach cooperation willingness; then, a cooperation agency or third-party agency between them two is needed to maintain the cooperation between them in case cooperation is stopped because of some contradiction, students' employment efficiency and quality might be influenced. In conclusion, universities need to provide a good practice and learning platform for students, thereby laying good basis for students' later employment.

\subsection{Innovate and reform teaching contents, highlight key teaching points}

With the continuous development of the market, people begin to have different definitions of "talent", which proposes increasingly more rigorous demands on talents to some extent. Therefore, under the fierce competition, if students want to have high employment rate, they need to improve themselves when at college. However, students' professional courses are tedious, so they "are 
unable to do what they hope to do". In order to improve this condition, universities need to improve teaching content for students and educators need to avoid teaching a large amount of teaching content, i.e., they should try to prevent students from finding real key points in the tedious professional courses. Therefore, practical teaching in universities need to innovate and reform teaching contents, and educators need to teach key points with strong practical skills, highlight key teaching points, avoid taking too much time in teaching normal points, ask students to grasp key points in learning process and further grasp key points. Meanwhile, students are able to spare some free time for self-study in this way.

\subsection{Reform flexible and efficient assessment system}

If universities want to train students to comprehensive talents with high market competitiveness, they not only need to reform and innovate practical teaching content, but also need to reform assessment system. Students can not only realize their standard and disadvantages by flexible assessment system, but also universities can formulate pertinent teaching program according to test results. When formulating assessment system for students, educators need to consider the special requirements of students, test frequency, test complexity and whether the test can test students' practical operation ability. In this way, not only relative personnel can grasp students' professional ability, but also students are provided with an opportunity of self-identification. Most importantly, this way can exert effects well.

\subsection{Investing in constructing training base and cultivation of teachers}

In practical teaching, training base and teachers' professional ability both have direct influence on teaching results. Therefore, universities need to invest in a large amount of capital for the construction of training base and improving teachers' professional skills and qualities. In the process of training base construction, relative facilities of training base need to be updated in time and more practical operation opportunities need to be provided to students, thereby presenting the specialty and practicability of practical teaching and students can understand the employment situation in society sooner. During practical teaching period, universities need to provide more training opportunities for teachers. For example, hold forum, exert forums and communication meetings. In this way, teachers' knowledge system structure can be transformed, and their professional skills and qualities can be enhanced. In addition, universities can grant certain subsidies to teachers with strong skills or more certificates, thereby improving teaching enthusiasm and accelerating teaching process.

\section{Conclusion}

Application-oriented universities do not receive expected results during practical teaching process mainly because of the following elements, traditional teaching methods, teachers' poor professional skills and qualities, unsuitable assessment system, and insufficient attention to students' practical skill standard. Therefore, if universities want to cultivate comprehensive talents, they need to improve the above conditions and innovate and reform practical teaching.

\section{References}

[1] Liu Junli. Considerations on MOOC's Facilitation Role in the Reform of Practical Teaching of Application-oriented Universities[J]. Journal of Chengdu Normal University. 2016(12)

[2] Guo qingwei, Li Yutao. research on structural mechanics teaching reform in local applied undergraduate colleges [j]. journal of Nanyang normal university.2017 (03)

[3] Zheng shuping. reform and experience of undergraduate teaching in American universities [j]. journal of Hubei institute of economics (humanities and social sciences edition) .2017 ( 02 )

[4] Huang Zhilin. research on macro-economics undergraduate teaching reform in big data era [j]. China's management information technology.2017 (06) 
[5] feng mingjia, Xin zhiya, Sun Lina. exploration on teaching reform of interchangeability and technology measurement course for application-oriented undergraduate [j]. Heilongjiang science and technology information.2017 (12)

[6] dong fulong, yi kechuan, Li Jin, Zheng fengju. pro / e curriculum reform and practice in application-oriented undergraduate colleges [j]. Shandong industrial technology.2017 (09) 